\title{
Bitcoin and its Legality from Shariah Point of View
}

Yusuf Sani Abubakar

Ahamad Faosiy Ogunbado

Mpawenimana Abdallah Saidi

\author{
Islamic Business School (IBS), College of Business \\ Universiti of Utara Malaysia, Malaysia (UUM) \\ Islamic Development Management Universiti Islam Sultan \\ Sharif Ali (UNISSA), Brunei, Darussalam \\ Universiti Malaysia Sarawak (UNIMAS)Sarawak, Malaysia
}

Bitcoin is a type of cryptocurrency and the most successful in blockchain management. It has become famous in recent years. The critical aspects of cryptocurrency are its legitimacy, source of money laundering, tax evasion, lack of regulation etc. The aim of this study is to explore the view of Muslim scholars on the legality of bitcoin with respect to Shariah. The study adopts doctrinal approach which utilizes descriptive approach of qualitative research methodology which relies on secondary data in form of text books, journals, newspapers, related websites etc. The study found that Muslim scholars are divided on the issue. A part of them completely rejected bitcoin and considered it against Shariah principles. On the other hand, some Muslim scholars believe bitcoin does not contradict Islamic principles and therefore may be used, however with certain conditions. The researchers tend to support the proponents' view as most of the opponents' grounds for the rejection are temporary in nature which may be covered through policy regulations.

Keywords: Bitcoin, Shariah, cryptocurrency, blockchain management, Islamic

\section{Introduction}

Bitcoin is a contemporary phenomenon that emerged in recent years. It is considered the most successful in blockchain management and it is also a type of cryptocurrency. Bitcoin is made by bitcoin tissues depending on the demands and needs of bitcoin which is done systematically according to the precise mathematical calculations. Furthermore, bitcoin is a payment network based on peer-to-peer technology and open source. Every bitcoin transaction is stored in bitcoin database. And upon completion of a transaction by a seller and buyer with bitcoin, it would be automatically recorded in the bitcoin database network.

The process of generating or emitting bitcoin is known as mining. The name 'mining' gives the impression as if something valuable such as gold is being mined. The mining process requires substantial amount of resources and energy. Bitcoins' emission has been estimated to maximum of 21 million. Moreover, there are quantitative and temporary restrictions on bitcoin mining. Hence, participants would always know the number of bitcoins that will appear in the market in a particular period of time. Currently, bitcoins are generally exchanged for US dollars lone (Oziev et al 2018).

There are various disadvantages attached to the usage of bitcoin as currency. For example, there is no legal body responsible for the regulation of bitcoin currencies. Thus, in case of abuse or misuse e.g. money laundering, theft, fraud etc. no body shall be held responsible. Cryptocurrencies can also be used to evade tax. 
Although, this problem is not noticeable at the moment, however, in the future states face the danger of missing high revenues. Another grave issue is the geographical locations of the users. It is obvious that cyberspace is not under jurisdiction of any country in the world. Although, various companies from different countries in the world use internet, but it is still within the legislation of their countries. Therefore, any emission of cryptocurrencies in the internet is perceived as a product produced outside jurisdiction of any country, and is also considered as an imported commodity that is subject to custom clearance and taxation. However, cryptocurrencies may be allowed to be freely circulated if it is legalized by a country which can be bought and sold.

Generally, Muslim scholars are divided into two groups on the issue of legality of bitcoin under Shariah. A part of them accept its legality under Shariah, whereas others believe it contradicts Shariah principles. This study will attempt to summarize views of some of these Muslim scholars on the permissibility and prohibition of bitcoin from the Islamic point of view, and conclude by presenting the researchers' view on the issue.

\section{Methodology}

This paper is a library based research. The researchers adopted qualitative method in conducting the research. According to Sekaran and Bougie (2013), qualitative data are data in form of words. Thus, the secondary data are collected from books, journals, academic magazines, websites etc. Content analysis was used in analyzing the data.

\section{Salient characteristics of Bitcoin}

Basically, a blockchain management system is a self-reliant system used to transfer numerical values from one account to another and in that course no value would be lost between accounts in transit. Indeed, bitcoin is considered the most successful in the blockchain management system. Bitcoin and its like are copies of a piece of software running on users' computers who communicate with each other via the internet and the copies are updated approximately after every ten minutes (Nakamoto 2008). Actually, the capitalized (Bitcoin) refers to the software and the network of users, while the lower-case (bitcoin) is the unit of account in the system (Evans 2015). Furthermore, bitcoin is a type of cryptocurrency. Cryptocurrency is a digital currency which is not an official currency and not regulated by governments. Bitcoin is a type of digital currency that first emerged in 2009 which was introduced by Satoshi Nakamoto as a cryptography-based digital currency. Bitcoin is made by bitcoin tissues depending on the demands and needs of bitcoin which is done systematically according to the precise mathematical calculations. Furthermore, bitcoin is a payment network that is based on peer-to-peer technology and also open source. Whenever a bitcoin transaction occurred it is stored in the bitcoin database. And upon completion of a transaction by a seller and buyer with bitcoin, it would be automatically recorded in the bitcoin database network (Darmawan, 2014; Bohme, et al. 2015; Moore and Christin 2013; Decker and Wattenhofer, 2013; Barber, et al., 2012).

The fact that cryptocurrency is being used for transactions such as buying and selling and also as savings and exchange for other currencies, hence it has similarities to other unregulated money circulating on the internet (Oziev et al 2018). In working with cryptocurrency, for example bitcoin, there are different levels as follows (Oziev et al 2018): 
Firstly: bitcoins may be owned by any legal or physical person. In order to do that, a person needs to download a special software program on his computer that will allow him to have a wallet where he can be storing the bitcoins inside. Bitcoins may be purchased using fiat money such USD, EURO, Ringgit etc. and afterward stored in the wallet.

Secondly: bitcoins may be generated or emitted through downloading a special software program on the computer. This software solves sophisticated mathematical equations/puzzles that are generated by the bitcoin system. Any user who is able to solve the equation known as hash would be rewarded by a bitcoin. This process of generating or emitting bitcoin is known as mining. The name 'mining' gives the impression as if something valuable such as gold is being mined. The mining process normally is time consuming and also consumes large amount of electricity.

Thirdly: the user having owned the bitcoin may now perform transactions with or without commission. The user will propose a commission to prioritize his deal in about 10 minutes, while the non-commission transaction may take longer which may reach few hours. There is high security given to bitcoin besides encryption by using blockchain technology. This means that bitcoin owner possess a full database of all transactions that took place from the first time they appeared. However, the database is anonymous and thus it is mostly impossible to know the exact location of the bitcoin holders (Oziev et al 2018).

Normally, the transaction of bitcoin works in this manner. Assuming that a person sold something and received payment in the form of bitcoin in his wallet. Now, the record would be automatically sent to all computers that are connected to the bitcoin system. Meanwhile, all bitcoin owners would know that a particular transaction has taken place. Now, the same person decides to buy something using his bitcoin to make payment, as he instructs his wallet to transfer the amount to the other wallet, the computer would send a request to all the computers that are connected to the bitcoin system in order to verify the validity of the transaction. And if they give confirmation, the amount would be transferred and all the computers would be sent a new message requesting the addition of a new record to the database, and the bitcoin amount would be deducted from the buyer's wallet to the seller's wallet (Oziev et al 2018).

In a situation where a person attempts to cheat by duplicating bitcoins before selling the original ones he has purchased, where he tries to sell the duplicate one first, the computers of other participants will automatically reject the transaction as the original and correct transaction has been earlier recorded. Thus, a hacker cannot easily succeed in conducting a fraud or fake transaction. This is because, in order to succeed in hacking the system, the hacker will have to hack all the computers as well as change the whole database of the system, and this is very unlikely or almost impossible due to the high number of participants estimated to have reached 3 million as of the beginning of 2017. Therefore, to succeed in hacking, it is compulsory to mobilize the computing power which is equivalent to almost half of the world's current computers. According to some expert, even if 400 billion computers are used to hack the system, no any serious disruption will likely occur save causing delay in certain transactions of about ten minutes (Oziev et al 2018).

Cryptocurrencies do not have backing of real estate. But, so far no hacking issue has been reported, and hence we may confidently assert that they are unique and may attract the interest of those users looking for an alternative to fiat money. There were instances where attempts to back cryptocurrencies with certain assets were made, particularly gold. However, if done, the asset backed cryptocurrencies with the assets will become an ordinary mechanism to attract investors to invest in a project guaranteed by real collateral and it will cease to be a cryptocurrency (Oziev et al 2018). 
Bitcoins' emission amount has been estimated at maximum of 21 million. Moreover, there are also quantitative and temporary restrictions on generating/mining of the bitcoins. Hence, participants would always know the number of bitcoins that will appear in the market in a particular period of time. Currently, bitcoins are generally exchanged for US dollars lone (Oziev et al 2018).

However, there are various disadvantages attached to the usage of bitcoin as currency. For example, there is no legal body responsible for the regulation of bitcoin currencies. Thus, in case of abuse or misuse e.g. money laundering, theft, fraud etc. no body shall be held responsible (Nurhisam 2017).

Moreover, one of the major problems of cryptocurrencies is the fact that it may be used to evade tax. The bitcoin owners due to their anonymity can carry out any type of operation such as avoiding tax payment or reporting to the tax authority. Although, this problem is not noticeable at the moment, however, in the future states face the danger of missing high revenues (Oziev et al 2018).

Another grave issue is the geographical locations of the users. It is obvious that cyberspace is not under jurisdiction of any country in the world. Although, various companies from different countries in the world use internet, but it is still within the legislation of their countries. Therefore, any emission of cryptocurrencies in the internet is perceived as a product produced outside jurisdiction of any country, and is also considered as an imported commodity that is subject to custom clearance and taxation. However, cryptocurrencies may be allowed to be freely circulated if it is legalized by a country which can be bought and sold (Oziev et al 2018).

\section{Muslim scholars' opinion on bitcoin}

The debate of Muslim scholars on bitcoin revolves around the extent to which cryptocurrencies are in line with Shariah principles. Some scholars support while others oppose. Following are views of some of the scholars:

\section{Proponents}

Some scholars believe that cryptocurrencies comply with Shariah principles. For example, according to Oziev et al (2018), there is no clear evidence indicating that bitcoin is against Islamic principles. The fact that price of bitcoin has skyrocketed in recent months by hitting new heights (for example 20k USD for one bitcoin as of $17^{\text {th }}$ December 2017), is not an indication of its impermissibility from the Islamic point of view. If anything, it is just a sign of increase in the high demand of bitcoins. However, for bitcoin to be Shariah compliant the following must be observed (Oziev et al 2018).

Firstly: If bitcoin is acquired for saving purposes, it may be considered as impermissible, as the high instability attached to the exchange rate involves excessive risk (gharar) as well as participating in speculation (maysir). Thus, this element may be eliminated if the volatility related to exchange rate of bitcoins gets levelled with the major currencies of the world.

Secondly: bitcoins acquisition is permissible if it is done for the purpose of immediate payments for goods and services or currency exchange.

Thirdly: this is related to mining of the bitcoin itself. For the mining to be permissible, the goal behind it has to be noble. Thus, if the acquisition of the bitcoin by the miner would be utilized for payment of goods and services then it is permissible. Therefore, any commission obtained for approval of third parties transaction during the mining is considered permissible. But, if the miner's goal is to acquire and save the bitcoin with the 
hope of increase of price in the future, this is considered an act involving excessive risk (gharar) and speculation (maysir).

Fourthly: bitcoins do not have any significant contribution in impeding the gap of financial inequality between their owners. Furthermore, bitcoins seem to provide a cover and protect the anonymity of the participants and this help them in evading taxes.

Fifthly: There is no certainty as to whether bitcoin is actually an innocent currency as being claimed by some or it is just an instrument in the hands of particular smart people who may likely have hiding plan they want to achieve. Thus, transactions using bitcoin should be very limited.

Bakar (2018) believes that bitcoin is not against Shariah principles. He opines that Blockchain could even help in fighting money-laundering. He disagrees with making cryptocurrencies forbidden under Shariah due to its fluctuating value. He said both fiat money and cryptocurrencies are based on trust. He argues that the value of fiat money also fluctuates internationally, but still it is not considered forbidden on this basis, although this is also a risk.

Al-Zahrani (2016) says: "Crypto currency is one of the types of currencies/money that emerged as a result of the process of creating and developing money. In other words, at first it was an ordinary barter, then gold and silver coins, and then paper money and now virtual money, which are crypto-currencies. And this is normal". Furthermore, Mufti Abdul Qadir Barakatullah states that: "I am convinced that cryptocurrencies can be an effective tool for the further development of Islamic finance." Additionally, he cited the famous principle among the Muslim scholars that any commodity that may be used by a society as a means of payment may be perceived as money (https://www.youtube.com/watch?v=OyG5YYY-4D4).

Mufti Muhammad Abu Bakar, a Sharia adviser and compliance officer at Blossom Finance in Jakarta, published a paper on whether Bitcoin is Halal (permitted) or Haram (forbidden) on Tuesday 10 April. The paper essentially ruled that in certain cases, Bitcoin can indeed be Halal, permitted. An excerpt read: "In Germany, Bitcoin is recognized as a legal currency and therefore qualifies as Islamic money in Germany. In countries such as the US, Bitcoin lacks official legal monetary status but is accepted for payment at a variety of merchants, and therefore qualifies as Islamic customary money" (https://www.ccn.com/bitcoin-declared-compliant-with-sharia-law-price-surges).

According to Kahf (2017), bitcoin like any other currency is considered money within its community, and therefore to exchange it with other currencies will be subject to some conditions that are applicable in the exchange of currencies from the Shariah point of view. The conditions are: (1) exchange must be done on spot; (2) there shall not be speculations on currencies. That means the intention must be using the currency for buying and selling and not only exchange of currency. However, he believes that until bitcoin is traded in the open market just like other currencies, there is still big chance of manipulation.

The fatwa centre of South African Islamic seminary, Darul Uloom Zakariyya believes that Bitcoin fulfils the condition of mal and thus it is allowed for trade. But, for it to be qualified as currency, it has to be approved by relevant government authorities (Abu-Bakar 2017).

From the aforementioned proponent views, some of their justification for permitting usage of bitcoin may be summarized as follows:

1- Bitcoins acquisition is permissible if it is done for the purpose of immediate payments for goods and services or currency exchange;

2- Bitcoin mining may be permissible if the goal behind it is noble; 
3- Bitcoin cannot be forbidden on the ground that its value fluctuates as even the value of fiat money also fluctuates internationally, but still it is not considered forbidden on this basis, although this is also a risk;

4- Bitcoin may be used as a legal currency if allowed by governments. For example, in Germany, Bitcoin is recognized as a legal currency and therefore qualifies as Islamic money in Germany. In countries such as the US, Bitcoin lacks official legal monetary status but is accepted for payment at a variety of merchants, and therefore qualifies as Islamic customary money;

5- Bitcoin is money within the community that recognizes it and thus, to exchange it with other currencies will be subject to some conditions that are applicable in the exchange of currencies from the Shariah point of view.

\section{Opponents}

Conversely, there are Muslim scholars who are against cryptocurrencies. For example, Sheikh Imran (2017) believes that any currency that does not have intrinsic value cannot be considered as valid money. Thus, in his opinion - only gold or silver money can meet the criteria of the Shariah.

According to Professor Ahmed Kamel Midin Meera, for any digital currency to be accepted by the Shariah, it has to be a measure of value and it has to be a monetary commodity. He believes that there must be a standard of weight on paper notes or electronic currencies to be recognized. Moreover, it has to be redeemable with a standard weight like gold. If not, it is just fiat money (Rabbit 2017).

According to the Directorate of Religious Affairs, or Diyanet, Turkey (2018), a state organisation dealing with religious matters, crypto-currencies were open to speculation, they were not appropriate for Muslims to use. Their decision states that: "Buying and selling virtual currencies is not compatible with religion at this time because of the fact that their valuation is open to speculation, they can be easily used in illegal activities like money laundering and they are not under the state's audit and surveillance (http://www.euronews.com/2017/11/28/bitcoin-is-not-compatible-with-islam-turkeys-religious-authoritiessay).

Egypt's Grand Mufti (2018) is of the opinion that bitcoin is forbidden in Shariah as it brings harm to individuals, groups and institutions. He compared trade of cryptocurrency to gambling. He further argues that bitcoin could negatively affect the legal safety of its traders and may ease money laundering affairs as well as contraband trades (http://aboutislam.net/muslim-issues/middle-east/egypts-grand-mufti-bans-bitcointrading/).

The fatwa centre of Palestine opines that bitcoin and cryptocurrency is forbidden from the Shariah point of view as firstly, the bitcoin issuer is anonymous and no government or central authority is behind the issuance. Secondly, bitcoin is considered a type of gambling as traders invest a lot of money in order to create bitcoin without guarantee of success as the miners try to solve mathematical puzzles in order to create bitcoin. Thirdly, bitcoin is subject to high speculation (Abu-Bakar 2017). According to Shaykh Haitam, bitcoin and other cryptocurrencies are prohibited and not compatible with Shariah as cryptocurrency is not backed by anything, but rather it is created out of nothing. Moreover, cryptocurrency is not a legal tender; it is neither under the supervision of any government nor any central monitoring/control system. Again, cryptocurrency can be easily used for money laundering and illegal purposes (Abu-Bakar 2017). 
Nashirah Abu Bakar et al (2017) believe that bitcoin is significantly associated with the element of uncertainty (gharar). This is because the bitcoin holder is anonymous. Thus, in case of any suspicious activity it would be difficult to track the real account holder. Moreover, bitcoin may be suitable for a limited usage, but in order to implement it in all sectors of the economy, there shall be a strong mandate as there is possibility of fraud in the absence of central authority. Furthermore, bitcoin may be easily hacked. Additionally, it has no physical form but only exist on the network. Again, it has no intrinsic value as it is not redeemable for another commodity such as gold. Likewise, the value of bitcoin is unstable due to high volatility.

From the above, the opponent reasons for disallowing bitcoin usage may be summarised as follows:

1- Any that any currency that does not have intrinsic value cannot be considered as valid money. Thus, only gold or silver money can meet the criteria of the Shariah;

2- For any digital currency to be accepted by the Shariah, it has to be a measure of value and it has to be a monetary commodity. There must be a standard of weight on paper notes or electronic currencies to be recognized. Moreover, it has to be redeemable with a standard weight like gold. If not, it is just fiat money;

3- Buying and selling virtual currencies is not compatible with religion at this time because of the fact that their valuation is open to speculation, they can be easily used in illegal activities like money laundering and they are not under the state's audit and surveillance;

4- Bitcoin is forbidden in Shariah as it brings harm to individuals, groups and institutions. It is compared to gambling;

5- Bitcoin and cryptocurrency is forbidden from the Shariah point of view as firstly, the bitcoin issuer is anonymous and no government or central authority is behind the issuance. Secondly, bitcoin is considered a type of gambling as traders invest a lot of money in order to create bitcoin without guarantee of success as the miners try to solve mathematical puzzles in order to create bitcoin. Thirdly, bitcoin is subject to high speculation;

After looking at the proponents' arguments, the researchers tend to support the proponents' view as most of the opponents' grounds for the rejection are temporary in nature which may be covered through policy regulations. A lot of their arguments may also be used to prohibit fiat money, but fiat money is recognized by Shariah today because it is well regulated by governments.

\section{Conclusion}

The study reveals that bitcoin is considered the most successful in blockchain management and it is also a type of cryptocurrency. However, there are various disadvantages attached to the usage of bitcoin as currency. For example, there is no legal body responsible for the regulation of bitcoin currencies. Thus, in case of abuse or misuse e.g. money laundering, theft, fraud etc. no body shall be held responsible. Moreover, one of the major problems of cryptocurrencies is the fact that it may be used to evade tax.

On the other hand, Muslim scholars are divided on the legality of bitcoin into two groups. Generally, the proponents of legality of using bitcoin from Shariah point of view believe that there is no clear evidence indicating that bitcoin is against Islamic principles. Moreover, fluctuating value of cryptocurrency is not sufficient to make it impermissible from the Shariah point of view as even fiat money encounters the same problem internationally. Again, there is a belief it may help in the development of Islamic finance and there is 
a principle among the Muslim scholars that any commodity that may be used by a society as a means of payment may be perceived as money. Cryptocurrency particularly bitcoin may be exchanged with other currencies subject to some conditions that are applicable in the exchange of currencies from the Shariah point of view. Furthermore, bitcoin fulfil the conditions of the condition of mal and thus it is allowed for trade. Conversely, the opponent of cryptocurrencies believe that any currency that does not have intrinsic value cannot be considered as valid money, and only gold or silver money can meet the criteria of the Shariah. Moreover, for any digital currency to be accepted by the Shariah, it has to be a measure of value and it has to be a monetary commodity, and there must be a standard of weight on paper notes or electronic currencies to be recognized and it has to be redeemable with a standard weight like gold. If not, it is just fiat money. Furthermore, bitcoin is significantly associated with the element of uncertainty (gharar). This is because the bitcoin holder is anonymous. Thus, in case of any suspicious activity it would be difficult to track the real account holder etc.

From the foregoing debate, the researchers tend to support the proponents' view as if a society agrees to use a particular commodity as a means of payment it may regarded as money. Again, cryptocurrency particularly bitcoin may be exchanged with other currencies subject to some conditions that are applicable in the exchange of currencies from the Shariah point of view, as it is just like fiat money, and hence they share same conditions of currency exchange as provided by Shariah. Thus, the researchers believe that most of the arguments of the opponents from the Muslim scholars are based on temporary problems which can be easily overcome with a proper regulation of cryptocurrencies particularly bitcoin by governments.

\section{References}

Abu Bakar, M. M. (2018), Islamic Scholar Says Bitcoin is Compliant With Sharia Law as Price Surges, https://www.ccn.com/bitcoin-declared-compliant-with-sharia-law-price-surges/, Accessed on 18/8/2018.

Abu Bakar, Nashirah, Rosbi, S., and Uzaki. K. (2017), "Cryptocurrency Framework Diagnostics from Islamic Finance Perspective: A New Insight of Bitcoin System Transaction”, International Journal of Management Science and Business Administration, Volume 4, Issue 1, PP 19-28

Abu-Bakar, M.M. (2017), Shariah Analysis of Bitcoin, Cryptocurrency, and Blockchain https://blossomfinance.com/bitcoin-working-paper. Accessed on 8/8/2018.

Al-Zahrani, S. A. (2016), Ruling on cryptocurrencies, https://www.youtube.com/watch?v=OyG5YYY-4D4. Accessed on 8/8/2018.

Bakar, D. (2018), Is Cryptocurrency Haram? The Chairmain Of BNM’s Shariah Advisory Council Says No. https://vulcanpost.com/632153/haram-cryptocurrency-syariah-advisory-council/. Accessed on 8/8/2018.

Barakatullah, M.A.Q. http://fin-future.com/category/financial-services/crypto-currencies/. FinFuture Forum. Inc. Publications.

Barber, S., Boyen, X., Shi, E. and Uzun, E. "Bitter to better - how to make bitcoin a better currency," in Financial Cryptography 2012, vol. 7397 of LNCS, 2012, pp. 399-414.

Böhme, R., Christin, N., Edelman, B., and Moore, T. (2015), "Bitcoin: Economics, technology, and governance", The Journal of Economic Perspectives, 29(2), 213-238. Crossref

Decker, C. and Wattenhofer, R., "Information propagation in the Bitcoin network," IEEE P2P 2013 Proceedings, Trento, 2013, pp. 1-10.doi: 10.1109/P2P.2013.6688704 Crossref 
Directorate of Religious Affairs, or Diyanet, Turkey. (2018), Bitcoin 'not compatible with Islam http://www.euronews.com/2017/11/28/bitcoin-is-not-compatible-with-islam-turkeys-religiousauthorities-say. Accessed on 8/8/2018.

Egypt's Grand Mufti. (2018), Egypt's Grand Mufti Bans Bitcoin Trading, http:/ /aboutislam.net/muslimissues/middle-east/egypts-grand-mufti-bans-bitcoin-trading/. Accessed on 8/8/2018.

Evans. C.W. (2015), Bitcoin in Islamic Banking and Finance, Vol. 3, No. 1, pp. 1-11 Hussain, S.I. https://www.youtube.com/watch?v=9czV1bronto retrieved on 08/08/2018.

Kahf, M. (2015), Fatwa on Bitcoin, http://lightuponlight.com/blog/fatwa-on-bitcoin-by-monzer-kahf/ retrieved on $08 / 08 / 2018$.

Moore, T., and Christin, N. (2013), Beware the middleman: Empirical analysis of Bitcoin-exchange risk. International Conference on Financial Cryptography and Data Security (pp. 25-33). Springer, Berlin, Heidelberg. Crossref

Nurhisam, L. (2017), "Bitcoin: Islamic Law Perspective”, Qudus International Journal of Islamic Studies, Volume 5, Issue 2

Oscar, D. (2014), Bitcoin Mata Uang Digital Dunia. Jakarta: Jasakom.com.

Oziev, G. \& Yandiev, M. (2018), Cryptocurrency from Shariah perspective retrieved from https://papers.ssrn.com/sol3/papers.cfm?abstract_id=3101981, on 20/07/2018.

Rabbit, G. (2017), A Cryptocurrency for the Islamic Financial Markets. Retrieved on 08/08/ 2018, https://cryptoinsider.com/cryptocurrency-islamic-financial-markets / 